\title{
On the Relevance of Considering the Intermolecular Interactions on the Prediction of the Vibrational Spectra of Isopropylamine
}

\author{
Ana M. Amado, ${ }^{1}$ Sónia M. Fiuza, ${ }^{1}$ Luis A. E. Batista de Carvalho, ${ }^{1}$ \\ and Paulo J. A. Ribeiro-Claro ${ }^{2}$ \\ ${ }^{1}$ Química-Física Molecular, Departamento de Química, FCTUC, Universidade de Coimbra, 3004-535 Coimbra, Portugal \\ ${ }^{2}$ Departamento de Química, CICECO, Universidade de Aveiro, 3810-193 Aveiro, Portugal
}

Correspondence should be addressed to Ana M. Amado; amado.am@gmail.com

Received 2 May 2013; Revised 19 August 2013; Accepted 18 September 2013

Academic Editor: Anton Kokalj

Copyright (c) 2013 Ana M. Amado et al. This is an open access article distributed under the Creative Commons Attribution License, which permits unrestricted use, distribution, and reproduction in any medium, provided the original work is properly cited.

The effects of implicitly considering the effects of hydrogen bonding on the molecular properties, such as vibrational frequencies, were inferred on the basis of DFT calculations. Several clusters of isopropylamine were assembled and theoretically characterized. The results showed that maximum H-bond cooperativity is achieved when the amine group acts simultaneously as donor and acceptor. The effect of $\mathrm{H}$-bond cooperativity manifests itself in the relative cluster stability and on the structural and vibrational frequency predictions. Referring to the vibrational frequencies it was found that the $\mathrm{NH}_{2}$ stretching and torsion vibrational modes are the most affected by the amine involvement in hydrogen bonding. Both stretching modes were found to be significantly redshifted relative to the monomer. The $\mathrm{NH}_{2}$ torsional mode, on the other hand, was found to be blueshifted up to $350 \mathrm{~cm}^{-1}$. Finally, the comparative study between the theory levels performed allows to conclude that the small 6-31G ${ }^{*}$ basis set is able to stabilize weak $\mathrm{C}-\mathrm{H} \cdots \mathrm{N}$ interactions as long as the new dispersion corrected DFT methods are considered. The impairments observed with conventional DFT methods for describing weak interactions may be overcome with the improvement of basis set, but the associated increase of computational costs may turn the calculations unfeasible.

\section{Introduction}

Intermolecular interactions play an important role in many areas of chemistry and biology, being important in phenomena such as solvation, molecular and macromolecular structure, supramolecular chemistry, and molecular recognition [1-5]. In condensed phase samples (liquid or solid), two types of intermolecular interactions may be of particular relevance, namely, the effects of the interactions between close-lying molecular neighbours (short range intermolecular interactions) and the effects of the surrounding medium on the molecular aggregates formed (medium-to-long range intermolecular interactions). The occurrence of these interactions may have a pronounced effect on the experimental spectra, such as vibrational ones, turning their assignment a difficult task.
Quantum chemical calculations are widely recognized as a powerful and helpful methodology for predicting and assigning experimental vibrational spectra. However, most of the theoretical calculations are performed considering the isolated molecule. By neglecting the effect of potential intermolecular interactions, significant deviations from the experimental data are frequently observed. This is particularly important when amine systems are targeted as they are prone to form extensive intermolecular hydrogen bond networks, with each $\mathrm{NH}_{2}$ group being able to establish up to three intermolecular interactions with neighbouring groups-two as a donor and one as an acceptor. Moreover the occurrence of multiple hydrogen bonds involving the same amine group opens up the possibility of hydrogen bond cooperativity [6-11]. 
In this context, the main goal of the present work is to infer the relevance of considering these intermolecular effects on the theoretical predictions of the vibrational spectra of aliphatic amines. Isopropylamine (2-aminopropane, iPram) was selected as a case study since, as a small-sized molecular system, it allows the study of different clusters, of increasing dimension and complexity, using different theory levels at a permissive computational cost. In the present work, molecular clusters of up to four iPram units, held by $\mathrm{N}-\mathrm{H} \cdots \mathrm{N}$ and/or $\mathrm{C}-\mathrm{H} \cdots \mathrm{N}$ intermolecular interactions, were considered.

\section{Theoretical Calculations Description}

Calculations were performed on a PC computer, using the Gaussian 09W (G09W) program [12]. The all-electron basis set $6-31 G^{*}$ was used in all calculations. The authors are aware of the smallness of the basis set used. Nevertheless, its use is justified as the present work is part of a larger project that aims to study larger aliphatic amines and their palladium and platinum complexes.

Six DFT methods were implemented in G09 under the designations PW91PW, B3LYP, mPW1PW, B971, B97D, and wB97XD. The use of these distinct DFT methods allows to infer on the effect of using either pure (PW91PW) or hybrid (B971, mPW1PW, and B3LYP) density functionals and on considering (or not) the dispersion and long-range effects (B97D and wB97XD). Several studies have shown that the conventional DFT methods, either pure or hybrid, tend to underestimate the interaction energies of hydrogenbonded systems [7, 10, 13-17]. The inclusion of semiempirical corrections for dispersion (as in B97D) coupled with longrange correction (as in wB97XD) has been suggested as viable routes for achieving a better description of the intermolecular interactions, including the interaction energies, without compromising the computational efficiency $[13,15,17,18]$. Testing hybrid B971 DFT seemed relevant as it is a modification of the hybrid B97 method, the parent DFT of both dispersion corrected DFTs considered [19]. Some additional calculations were performed on specific objectives and, therefore, are presented in the text where appropriate.

As stated previously, the present work is aimed at gauging the cumulative effect of different hydrogen bonds involving a given molecular group (in the present case, a primary amine $\mathrm{NH}_{2}$ group) on the theoretical predictions of molecular properties, such as vibrational frequencies. Three main effects were targeted: (i) the relative stabilization relevance of the distinct $\mathrm{H}$-bond donor groups (that is, the relative stabilizing effect of $\mathrm{N}-\mathrm{H} \cdots \mathrm{N}$ and $\mathrm{C}-\mathrm{H} \cdots \mathrm{N}$ interactions), (ii) the relative preference of the amine group to act as a donor (d) or as an acceptor (a), and finally, (iii) the improvements achieved by fulfilling the hydrogen bonding capabilities of the amine group. In view of these goals, different cluster geometries were assembled on a basis of a progressive increase of the amino group involvement in hydrogen bonds (monomer $\rightarrow$ dimer $\rightarrow$ trimer $\rightarrow$ tetramer). The different cluster geometries studied are presented in Figure 1, along with the correspondent designations used throughout the work and type of intermolecular interactions present. All geometries were fully optimized without any symmetry constraints. All attempts made to assemble clusters including $\mathrm{C}_{(1)}-\mathrm{H} \cdots \mathrm{N}$ interactions failed as all converged to one of the clusters presented in Figure 1.

Lines of evidence from the literature show that counterpoise correction (CP) during the gradient optimisation of molecular complexes, such as molecular self-associated clusters, has a pronounced effect on the calculated results $[10,14,17]$. Thus, to account for the basis set superposition error (BSSE) all cluster geometries were reoptimized within the scheme of Boys and Bernardi [20] as implemented in G09w [12] under the keyword counterpoise.

In all cases, vibrational frequency calculations were performed, at the same theory level, to verify its correspondence to a real minimum (no negative eigenvalues) and to estimate both the zero-point vibrational energy (zpve) and thermal energy corrections (all energy values considered in the present work are corrected values for both zpve and thermal contributions). The calculated frequency values have not been scaled by any factor, as relative raw effects are aimed for discussion.

Oligomers Overall Stability Evaluation. The relative stabilizing effect of the hydrogen bonding pattern of each oligomer (cluster) was evaluated by comparing two energetic parameters, namely, the cluster formation energy $\left(\Delta E_{\text {olig }}\right)$ and the cooperative effect between multiple $\mathrm{H}$-bonds (CEHB). The $\Delta E_{\text {olig }}$ value of each cluster $(\mathbf{O} n)$ was determined as

$$
\Delta E_{\text {olig }}(\mathbf{O} n)=-[E(\mathbf{O} n)-n \times E(\mathrm{M})],
$$

where $n$ represents the number of iPram units forming the cluster and $E(\mathrm{M})$ represents the energy determined for the monomer. The corresponding CEHB values, on the other hand, were determined using the expression

$$
\begin{aligned}
\operatorname{CEHB}(\mathbf{O} n)= & \Delta E_{\text {olig }}(\mathbf{O} n) \\
& -\left(i \times \Delta E_{\text {olig }}(\mathbf{O} \mathbf{2} \mathbf{a})+j \times \Delta E_{\text {olig }}(\mathbf{O} 2 \mathbf{b})\right),
\end{aligned}
$$

where coefficients $i$ and $j$ stand, respectively, for the number of $\mathrm{N}-\mathrm{H} \cdots \mathrm{N}$ and $\mathrm{C}-\mathrm{H} \cdots \mathrm{N}$ interactions present in the cluster.

\section{Results and Discussion}

3.1. Energetic Analysis. Figure 2 shows the variation of the $\mathrm{CP}$-uncorrected $\Delta E_{\text {olig }}$ values as a function of oligomer size and type of intermolecular interactions-(A) oligomers presenting only $\mathrm{N}-\mathrm{H} \cdots \mathrm{N}$ interactions (group I) and (B) oligomers also containing $\mathrm{C}-\mathrm{H} \cdots \mathrm{N}$ contacts (group II). The variation of the CP-corrected $\Delta E_{\text {olig }}$ values is presented in Figure S1 of the Supplementary Material (see Supplementary Material available online at http://dx.doi.org/10.1155/2013/682514).

The first evidence that stands from Figure 2 and S1 is the difficulty encountered by the conventional DFT methods in describing the $\mathrm{C}-\mathrm{H} \cdots \mathrm{N}$ intermolecular contact. In the case of the CP-uncorrected results (Figure 2) this impairment is only observed with B971, which is unable to stabilize the O3c cluster. All attempts made to stabilize the $\mathbf{O 3 c}$ geometry 


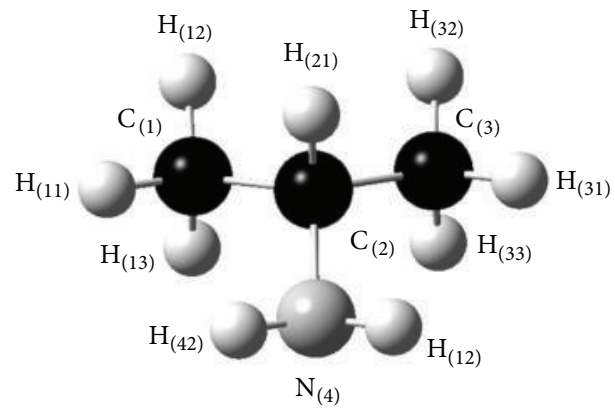

(a)

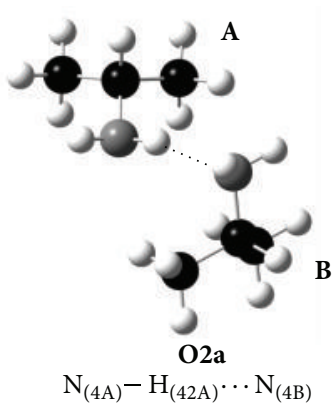

(b)

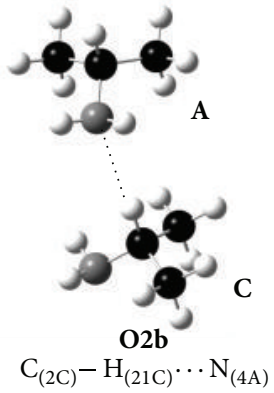

(c)

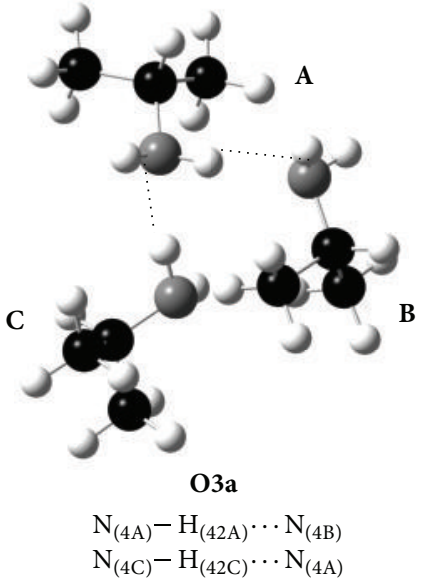

(d)

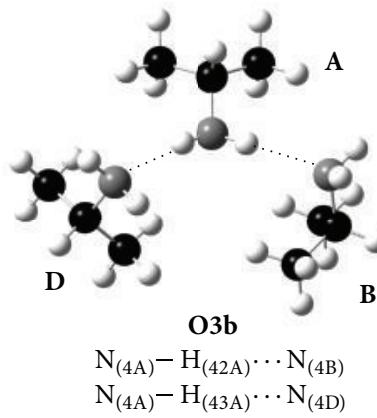

(e)

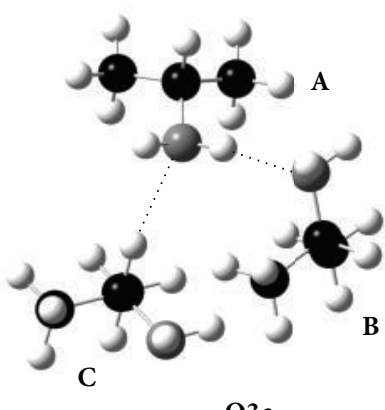

O3c

$$
\begin{aligned}
& \mathrm{N}_{(4 \mathrm{~A})}-\mathrm{H}_{(42 \mathrm{~A})} \cdots \mathrm{N}_{(4 \mathrm{~B})} \\
& \mathrm{C}_{(2 \mathrm{C})}-\mathrm{H}_{(21 \mathrm{C})} \cdots \mathrm{N}_{(4 \mathrm{~A})}
\end{aligned}
$$

(f)

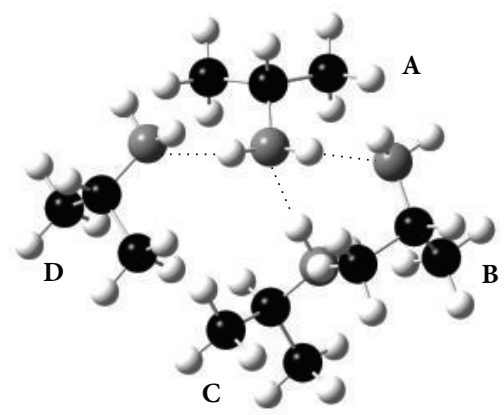

$$
\begin{gathered}
\text { O4a } \\
\mathrm{N}_{(4 \mathrm{~A})}-\mathrm{H}_{(42 \mathrm{~A})} \cdots \mathrm{N}_{(4 \mathrm{~B})} \\
\mathrm{N}_{(4 \mathrm{~A})}-\mathrm{H}_{(43 \mathrm{~A})} \cdots \mathrm{N}_{(4 \mathrm{D})} \\
\mathrm{C}_{(4 \mathrm{C})}-\mathrm{H}_{(43 \mathrm{C})} \cdots \mathrm{N}_{(4 \mathrm{~A})}
\end{gathered}
$$

(g)

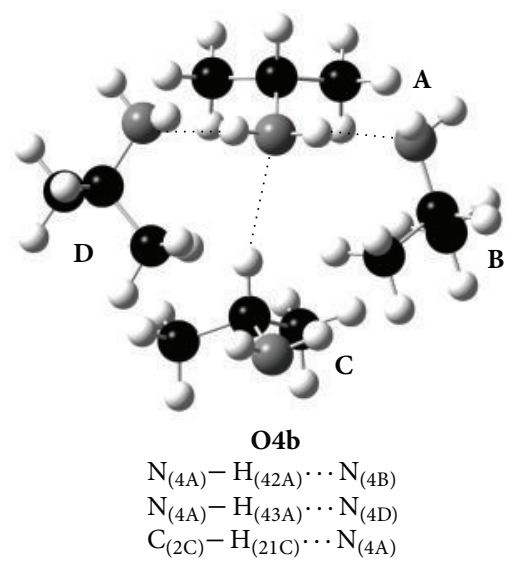

(h)

FIGURE 1: Representation of the different oligomeric species considered in the work. In all cases, each iPram unit was considered in the trans-form. The atom numbering used throughout the text and tables is presented.

failed with convergence to O3a. The same impairment was encountered when using the MP2 formalism (results not shown). When the CP-corrected calculations are gathered (Figure S1), it is found that the inability to stabilize O3c cluster is extended to the remaining conventional DFTs.
Moreover, MP2 and all conventional DFT methods, but B971, also become unable to stabilize the dimeric form O2b.

The impairment of stabilizing iPram clusters held by $\mathrm{C}-\mathrm{H} \cdots \mathrm{N}$ intermolecular contact affects more strongly the 


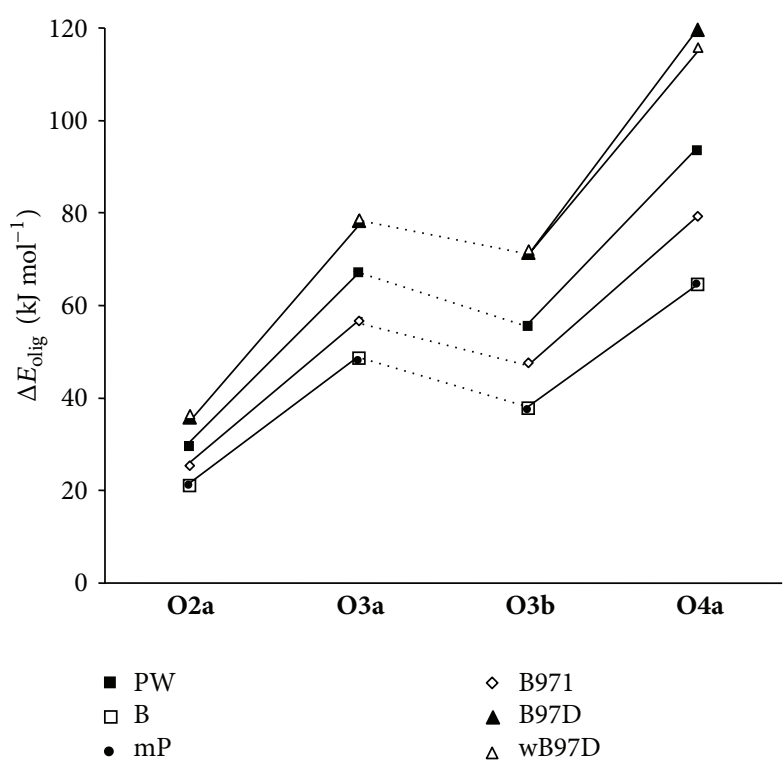

(a)

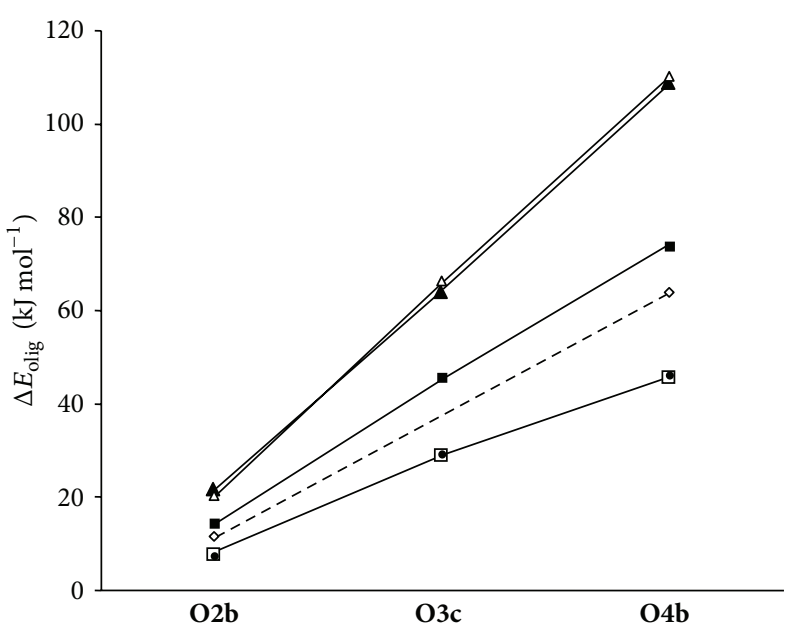

(b)

FIgURE 2: Variation of the CP-uncorrected $\Delta E_{\text {olig }}$ as a function of oligomer size and DFT: (a) oligomers presenting just $\mathrm{N}-\mathrm{H} \cdots \mathrm{N}$ interactions (group I) and (b) oligomers also $\mathrm{C}-\mathrm{H} \cdots \mathrm{N}$ contacts (group II).

B3LYP calculations. In fact, performing CP correction turns the B3LYP/6-31G ${ }^{*}$ calculations unable to stabilize either of the group II clusters. This impairment of B3LYP calculations has been correlated with the underestimation of the dispersion interactions by this DFT method [21]. In this context, and only to infer on the importance of the basis set size for this B3LYP impairment, calculations were performed at the B3LYP/6-311++ $\mathrm{G}^{* *}$ theory level (with and without CP correction). The results showed that the improvement given to the basis set allows to overcome the limitations of the calculations B3LYP to stabilize the $\mathrm{C}-\mathrm{H} \cdots \mathrm{N}$ intermolecular contact. The relative ordering of the different adducts as a function of the magnitude of the $\Delta E_{\text {olig }}$ is the same as encountered with the B97D/6-31G ${ }^{*}$ and $\mathrm{wB} 97 \mathrm{XD} / 6-31 \mathrm{G}^{*}$ calculations. In fact, the only clear difference encountered between those calculations refers to the magnitude of the $\Delta E_{\text {olig }}$ values, being the $\mathrm{B} 97 \mathrm{D} / 6-31 \mathrm{G}^{*}$ and $\mathrm{wB} 97 \mathrm{XD} / 6-31 \mathrm{G}^{*}$ values significantly overestimated relatively to the B3LYP/6$311++G^{* *}$ results. On the other hand, using the larger 6$311++\mathrm{G}^{* *}$ basis set leads to a dramatic increase of the computational costs, which rapidly turn the calculations prohibitive as amine size and complexity increase.

With no surprise, the magnitude of the interaction energies increases with cluster size and number of $\mathrm{N}-\mathrm{H} \cdots \mathrm{N}$ interactions established. In the case of the group II oligomers (Figures 2(b) and S1(b)), the interaction energy enhancement observed is almost linear with respect to cluster size. Regarding group I oligomers (Figures 2(a) and S1(a)), however, it is found that the magnitude of the $\Delta E_{\text {olig }}$ depends not only on cluster size and number of $\mathrm{N}-\mathrm{H} \cdots \mathrm{N}$ interactions but also on the overall $\mathrm{H}$-bond pattern assembled. It is found that a cumulative $\mathrm{d}$-a involvement of the amine group as in $\mathbf{O 3 a}$ is more stabilizing than the $\mathrm{d}$ - $\mathrm{d}$ involvement that characterizes
O3b by $7-12 \mathrm{~kJ} \mathrm{~mol}^{-1}\left(5-12 \mathrm{~kJ} \mathrm{~mol}^{-1}\right.$ in the case of the CPcorrected results).

Regarding the effect of performing BSSE correction, it is found that the $\Delta E_{\text {olig }}$ values of group II clusters are generally more affected than the ones related to group I oligomers. The conventional DFT methods are definitely more affected by BSSE than the dispersion corrected methods. This differential effect is probably related to the widely described deficiency of the former methods to cover dispersion energies [14, 16, 22].

An important issue in hydrogen bonding is the manifestation (or not) of H-bond cooperativity as the number of hydrogen bonds increases and the overall spatial arrangement varies. The concept is for long explored in the context of ligand-to-receptor binding but, more recently, has also been applied to the understanding of the behaviour of noncovalently bonded systems, such as molecular clusters $[10,11,23]$. Within the context of hydrogen bonding, positive cooperativity has been defined as the strength enhancement of existent intermolecular H-bond(s) as a new molecular unit is added to the growing aggregate [11]. Conversely, negative cooperativity refers to the weakening of the preexistent $\mathrm{H}$ bond(s) due to cluster growth.

One way of evaluating hydrogen bond cooperativity is by determining the overall stability enhancement achieved when a new intermolecular interaction is added to the preexistent $\mathrm{H}$-bond pattern. This can be done by analysing the variation of the $\mathrm{CEHB}$ values with cluster size. Note that by definition (2), a positive CEHB value corresponds to a positive cooperativity.

Figure 3 plots the CP-uncorrected and CP-corrected CEHB values as a function of DFT and cluster type. Recall that when BSSE correction was performed, the conventional functionals showed some difficulties in stabilising group II 
clusters, disabling some comparisons regarding the CP correction of the CEHB values obtained with the conventional DFT. In the cases where comparisons are possible, it is found that, in general, CP correction of the CEHB values, while affecting their absolute magnitude, does not affect their sign. The only exceptions are observed for the B97D and wB97XD $\mathrm{CEHB}$ values of $\mathbf{O} 3 \mathbf{b}$, which turn from negative to positive by CP correction, and for the B3LYP CEHB of O4a, which shows the opposite sign switch.

Based on the results obtained it is found that the enhancement of the interaction energies achieved by cluster size increase is not always interrelated with the occurrence of $\mathrm{H}$-bond cooperativity. According to the results of Figures 2 and S1, increase of cluster size from O2a to either O3a or $\mathbf{O} 3 \mathbf{b}$ is accomplished by a significant enhancement of $\Delta E_{\text {olig. }}$. However, the data of Figure 3 clearly show that only the transformation $\mathbf{O} 2 \mathbf{a} \rightarrow \mathbf{O} 3 \mathbf{a}$ is coupled with a meaningful positive $\mathrm{H}$-bond cooperativity. In the case of the $\mathbf{O} \mathbf{2} \mathbf{a} \rightarrow \mathbf{O} 3 \mathbf{b}$ transformation the predicted $\mathrm{CEHB}$ are either negative or just slightly positive. This observation suggests that changing from a d-a $\mathrm{H}$-bond profile $(\mathbf{O} 3 \mathbf{a})$ to a d-d pattern (O3b) leads to a decrease of $\mathrm{H}$-bond cooperativity. Reinforcing this observation is the significant $\mathrm{H}$-bond cooperativity predicted for the $\mathbf{O 3 c}$ cluster which, in spite of having a weak $\mathrm{C}-\mathrm{H} \cdots \mathrm{N}$ instead of a strong $\mathrm{N}-\mathrm{H} \cdots \mathrm{N}$, presents a high $\mathrm{CEHB}$ value. These results are clearly in line with the conclusions of Huyskens [24] for the involvement of $\mathrm{OH}$ groups in multiple hydrogen bonds. According to those results, the involvement of an $\mathrm{OH}$ group as an $\mathrm{H}$-bond donor strengthens its aptitude to act as an acceptor in a second $\mathrm{H}$ bond but weakens its ability to act as a donor in the second H-bond.

Increasing cluster size from trimer to tetramer by fulfilling the amine group $\mathrm{H}$-bonding capacities (O4a and O4b) increases positive $\mathrm{H}$-bond cooperativity. When the transformations $\mathbf{O 3 a} \rightarrow \mathbf{O} 4 \mathbf{a}$ or $\mathbf{O 3 c} \rightarrow \mathbf{O} 4 \mathbf{b}$ are regarded the CEHB values are increased, while following either of the transformations $\mathbf{O} 3 \mathbf{b} \rightarrow \mathrm{O} 4 \mathbf{a}$ or $\mathbf{O} 3 \mathbf{b} \rightarrow \mathbf{O} 4 \mathbf{b}$ leads to a sign switch of the CEHB from negative to positive.

Just aiming to infer on the maximum CEHB enhancement possible by incrementing cluster size, calculations of the CEHB values were performed for a forth trimericcluster (O3d; Figure 4). This iPram cluster simulates the trimeric water cluster predicted as the most stable $[25,26]$. As seen in Figure 4, the overall $\mathrm{H}$-bonding pattern around each iPram unit is the same as in O3a (d-a). However, in this trimeric cluster each iPram unit is linked to the other two through $\mathrm{N}-\mathrm{H} \cdots \mathrm{N}$ interaction, in one as an acceptor and in the other as a donor.

The graphical representation shown in Figure 4 compares the CP-uncorrected and CP-corrected CEHB values predicted for the $\mathbf{O 3 d}$ cluster with the ones obtained for both O3a and O4a clusters (only the B97D results are presented). As seen, the CEHB predicted for cluster O3d, with and without CP correction, largely overwhelm the corresponding $\mathrm{CEHB}$ values predicted for the equally sized $\mathbf{0 3 a}$ cluster. The magnitude of the CEHB values determined for O3d is very close to the ones associated with the larger-sized $\mathbf{O} 4 \mathbf{a}$ cluster.
This result, which was found to be independent of the theory level considered (including MP2), may reinforce the view that $\mathrm{H}$-bond cooperativity is mainly correlated with the presence of a d-a $\mathrm{H}$-bond arrangement around the amine group rather than to a fulfilling of its $\mathrm{H}$-bonding capacities.

3.2. Structural Analysis. Hydrogen bonding and cooperativity effects can manifest in other properties than energetic ones. From a structural point of view, the changes promoted on the length of the covalent bonds, directly involved in the interaction, and on the nonbonded $\mathrm{H}$...X distance may be particularly informative. Some studies report a close correlation between those structural parameters and the energetic of the intermolecular interactions as cooperative effects are concerned $[10,11]$.

Table 1 presents the CP-corrected bond length variations predicted for the $\mathrm{N}_{(4)}-\mathrm{H}$ and $\mathrm{C}_{(2)}-\mathrm{H}$ covalent bonds, relative to the monomer, and for the intermolecular distances between iPram units as a function of cluster type (Figure 1). The corresponding CP-uncorrected values are presented in Table S1 of the Supplementary Material.

Comparison of the CP-corrected and CP-uncorrected results (Table 1 versus Table S1) shows that correction of geometries for BSSE generally leads to a shortening of the $\mathrm{X}-\mathrm{H}$ distances ( $\mathrm{X}$ standing for either $\mathrm{N}_{(4)}$ or $\mathrm{C}_{(2)}$ ) and to a lengthening of the $\mathrm{H} \cdots \mathrm{N}$ intermolecular distances. This observation suggests that BSSE tends to overestimate the strength of intermolecular interactions, being in previously reported results on other hydrogen bonded molecular clusters $[14,17]$.

$\mathrm{CP}$ correction is found to affect distinctly the different DFT methods. The conventional DFT results are more strongly affected by CP correction than the dispersioncorrected results (B97D and wB97XD). Among the conventional DFT methods, B3LYP and MPW1PW seem to be the most affected ones. The high sensibility of B3LYP to $\mathrm{CP}$ correction translates in the abovementioned inability to stabilize group II clusters. The mPW1PW DFT, on the other hand, despite giving evidence of being able to stabilize $\mathbf{O 4 b}$ aggregate, predicted an $\mathrm{H} \cdots \mathrm{N}$ distance $(c a .341 \mathrm{pm})$ that is too long to be considered a real intermolecular distance.

Analysis of the variation trends of the $\mathrm{N}-\mathrm{H}$ and $\mathrm{C}-\mathrm{H}$ covalent bonds evidences the differential behaviour of the two structural parameters to the direct involvement in intermolecular interactions (Tables 1 and S1). Considering the monomer as reference, it is seen that while the establishment of $\mathrm{N}-\mathrm{H} \cdots \mathrm{N}$ interaction promotes the lengthening of the $\mathrm{N}-\mathrm{H}$ covalent bond, the formation of $\mathrm{C}-\mathrm{H} \cdots \mathrm{N}$ interactions leads to a shortening of the $\mathrm{C}-\mathrm{H}$ covalent bond. This distinct behaviour of the $\mathrm{N}-\mathrm{H}$ and $\mathrm{C}-\mathrm{H}$ covalent bonds has already been observed, both experimentally and theoretically, for other hydrogen bonded molecular clusters [11, 27-33], and has been correlated with a balance between two main effects that act in opposite directions. One is the net electron density gain in the $\mathrm{X}-\mathrm{H}$ bond region, that promotes a contraction of the covalent $\mathrm{X}-\mathrm{H}$ bond, and the other is the attractive interaction between the positively charged hydrogen atom and the electron rich acceptor $\mathrm{N}$-atom, which leads to lengthening of 


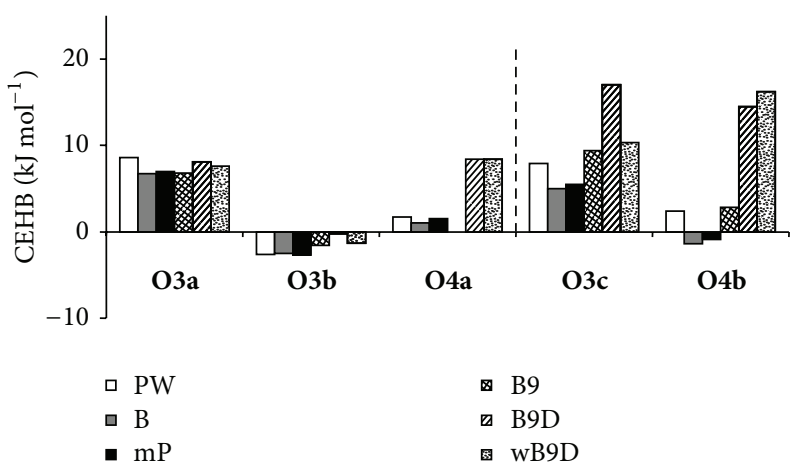

(a)

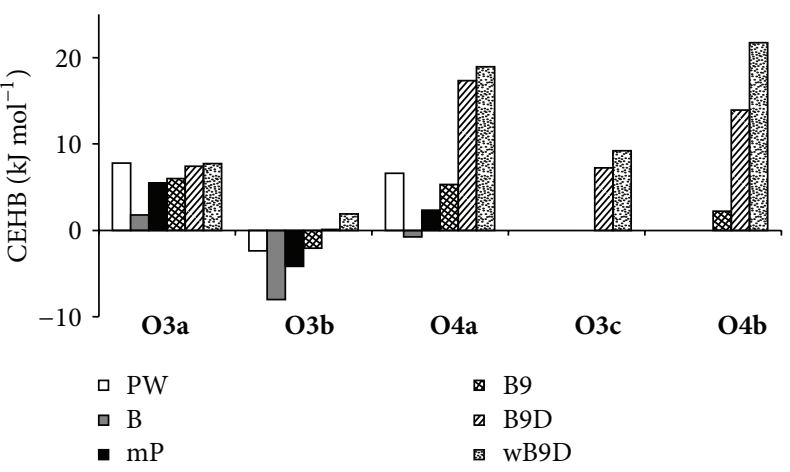

(b)

FIGURE 3: Variation of the CEHB values as a function of oligomer type and DFT, (a) prior and (b) after correction for BSSE.

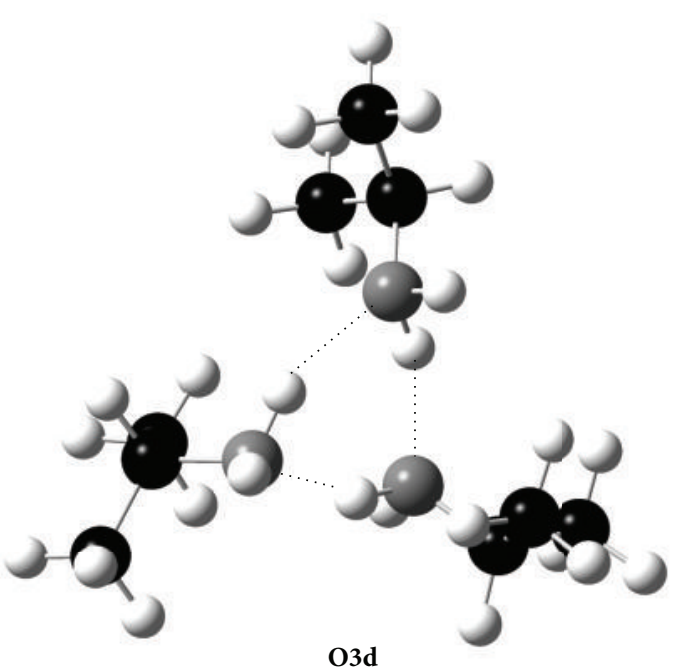

(a)

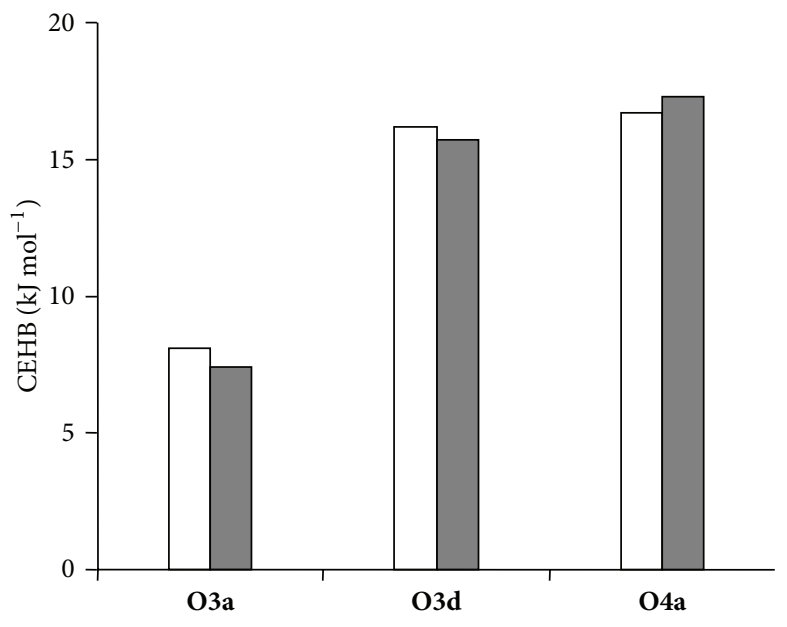

(b)

Figure 4: Comparison of the CP-uncorrected and CP-corrected CEHB values predicted by the B97D calculations for the O3d (which assembles the most stable geometry predicted for trimeric water clusters $[25,26])$, O3a, and O4a iPram clusters. The overall O3d optimized geometry is also depicted.

that bond $[28,29,34]$. The distinct behaviour observed for the $\mathrm{N}-\mathrm{H}$ and $\mathrm{C}-\mathrm{H}$ covalent bonds is explained by a distinct balance between those two effects, while in the $\mathrm{N}-\mathrm{H} \cdots \mathrm{N}$ close-contacts the preponderance of the $\mathrm{H} \cdots \mathrm{N}$ attraction explains the $\mathrm{N}-\mathrm{H}$ lengthening relative to the monomer, and in the case of the $\mathrm{C}-\mathrm{H} \cdots \mathrm{N}$ interaction, an electron density gain in the $\mathrm{C}-\mathrm{H}$ bond region overwhelms the effects of the attractive $\mathrm{H} \cdots \mathrm{N}$ interaction, leading to a relative $\mathrm{C}-\mathrm{H}$ bond shortening.

Opposing to what is observed for the $\mathrm{C}-\mathrm{H}$ bond distance, the lengthening magnitude predicted for the $\mathrm{N}-\mathrm{H}$ bonds is clearly dependent on the $\mathrm{H}$-bond pattern assembled. The establishment of the $\mathrm{d}$-a $\mathrm{H}$-bond pattern by incrementing O2a into O3a promotes a significant lengthening of the N$\mathrm{H}$ covalent bond, involved in the preexistent intermolecular interaction, relative to the monomer. A similar effect, despite being more subtle, is observed on passing from $\mathbf{O} 2 \mathbf{a}$ to $\mathbf{O 3 c}$, which also presents the $\mathrm{d}$-a $\mathrm{H}$-bond pattern but being the newly added interaction much weaker than in the former transformation. On the contrary, when the cluster incrementing is associated with the assembling of a d-d H-bond pattern $(\mathbf{O} 2 \mathbf{a} \rightarrow \mathbf{O} 3 \mathbf{b})$ it is found that the $\mathrm{N}-\mathrm{H}$ lengthening relative to the monomer is significantly reduced $(\mathrm{N}-\mathrm{H}$ distance in the trimer is shortened relative to the dimer). The effect of maximising the $\mathrm{NH}_{2}$-group involvement in hydrogen bonds on the $\mathrm{N}-\mathrm{H}$ bond length $(\mathrm{O} 3 \mathbf{a} \rightarrow \mathrm{O} 4 \mathbf{a}$ and $\mathrm{O} 3 \mathbf{b} \rightarrow \mathrm{O} 4 \mathbf{b})$ is the balance between the effects due to the simultaneous presence of the two $\mathrm{H}$-bond patterns, $\mathrm{d}$-a and $\mathrm{d}$ - $\mathrm{d}$, and the type of intermolecular interaction being added, $\mathrm{N}-\mathrm{H} \cdots \mathrm{N}$ or $\mathrm{C}-\mathrm{H} \cdots \mathrm{N}$. On the whole, the lengthening effects of the da pattern overwhelms the strengthening effects of the $\mathrm{d}-\mathrm{a}$ pattern $(\triangle \mathrm{N}-\mathrm{H}$ in $\mathbf{O 4 a}$ is smaller than in O3a but larger than in $\mathbf{O 3 b}$ ) and adding a $\mathrm{N}-\mathrm{H} \cdots \mathrm{N}$ interaction to the pattern has a more significant lengthening effect than adding a $\mathrm{C}-$ $\mathrm{H} \cdots \mathrm{N}$ interaction $(\triangle \mathrm{N}-\mathrm{H}$ in $\mathbf{O 4 a}$ is more significant than in O4b). 
TABLE 1: Selected CP-corrected N-H and C-H distance variations and $\mathrm{H} \cdots \mathrm{N}$ distances, in pm, calculated for each molecular cluster, as a function of oligomer type and DFT. Atom and cluster nomenclature according to Figure 1.

\begin{tabular}{|c|c|c|c|c|c|c|c|c|c|c|}
\hline & & & $\mathrm{J}-\mathrm{H} \cdots \mathrm{I}$ & teracti & & & & & $\cdot \mathrm{N}$ int & ion \\
\hline & O2a & O3a & O3b & O3c & O4a & O4b & & O2b & O3c & O4b \\
\hline & & & & & & PW91P & & & & \\
\hline$\Delta \mathrm{N}_{(4 \mathrm{~A})}-\mathrm{H}$ & 0.7 & 1.2 & 0.6 & - & 1.0 & 0.7 & $\Delta \mathrm{C}_{(2 \mathrm{C})}-\mathrm{H}$ & - & - & \\
\hline & & & 0.6 & - & 0.7 & 0.7 & & & & \\
\hline $\mathrm{N}_{(4 \mathrm{~A})}-\mathrm{H} \cdots \mathrm{N}_{(4 \mathrm{~B} / 4 \mathrm{D})}$ & 219.1 & 213.2 & 228.5 & - & 224.0 & 228.3 & $\mathrm{C}_{(2 \mathrm{C})}-\mathrm{H} \cdots \mathrm{N}_{(\mathrm{A})}$ & - & - & 297.6 \\
\hline & & & 228.9 & - & 226.5 & 227.3 & & & & \\
\hline $\mathrm{N}_{(4 \mathrm{C})}-\mathrm{H} \cdots \mathrm{N}_{(4 \mathrm{~A})}$ & & 211.6 & & & 210.0 & & & & & \\
\hline & & & & & & B3LY & & & & \\
\hline$\Delta \mathrm{N}_{(4 \mathrm{~A})}-\mathrm{H}$ & 0.5 & 0.8 & 0.4 & - & 0.6 & - & $\Delta \mathrm{C}_{(2 \mathrm{C})}-\mathrm{H}$ & - & - & - \\
\hline & & & 0.3 & - & 0.5 & - & & & & \\
\hline $\mathrm{N}_{(4 \mathrm{~A})}-\mathrm{H} \cdots \mathrm{N}_{(4 \mathrm{~B} / 4 \mathrm{D})}$ & 229.9 & 223.5 & 239.8 & - & 232.3 & - & $\mathrm{C}_{(2 \mathrm{C})}-\mathrm{H} \cdots \mathrm{N}_{(\mathrm{A})}$ & - & - & - \\
\hline & & & 239.6 & - & 232.3 & - & & & & \\
\hline $\mathrm{N}_{(4 \mathrm{C})}-\mathrm{H} \cdots \mathrm{N}_{(4 \mathrm{~A})}$ & & 221.6 & & & 218.7 & & & & & \\
\hline & & & & & & mPW1I & & & & \\
\hline$\Delta \mathrm{N}_{(4 \mathrm{~A})}-\mathrm{H}$ & 0.7 & 1.0 & 0.5 & - & 0.8 & 0.6 & $\Delta \mathrm{C}_{(2 \mathrm{C})}-\mathrm{H}$ & - & - & \\
\hline & & & 0.5 & - & 0.6 & 0.5 & & & & \\
\hline $\mathrm{N}_{(4 \mathrm{~A})}-\mathrm{H} \cdots \mathrm{N}_{(4 \mathrm{~B} / 4 \mathrm{D})}$ & 225.4 & 219.8 & 236.6 & - & 229.0 & 237.6 & $\mathrm{C}_{(2 \mathrm{C})}-\mathrm{H} \cdots \mathrm{N}_{(\mathrm{A})}$ & - & - & 340.7 \\
\hline & & & 235.3 & - & 235.6 & 235.5 & & & & \\
\hline $\mathrm{N}_{(4 \mathrm{C})}-\mathrm{H} \cdots \mathrm{N}_{(4 \mathrm{~A})}$ & & 217.9 & & & 217.2 & & & & & \\
\hline & & & & & & B971 & & & & \\
\hline$\Delta \mathrm{N}_{(4 \mathrm{~A})}-\mathrm{H}$ & 0.6 & 0.9 & 0.5 & - & 0.7 & 0.5 & $\Delta \mathrm{C}_{(2 \mathrm{C})}-\mathrm{H}$ & -0.4 & - & -0.4 \\
\hline & & & 0.5 & - & 0.6 & 0.5 & & & & \\
\hline $\mathrm{N}_{(4 \mathrm{~A})}-\mathrm{H} \cdots \mathrm{N}_{(4 \mathrm{~B} / 4 \mathrm{D})}$ & 226.7 & 219.5 & 233.4 & - & 228.5 & 233.8 & $\mathrm{C}_{(2 \mathrm{C})}-\mathrm{H} \cdots \mathrm{N}_{(\mathrm{A})}$ & 291.3 & - & 291.9 \\
\hline & & & 233.8 & - & 231.0 & 232.4 & & & & \\
\hline $\mathrm{N}_{(4 \mathrm{C})}-\mathrm{H} \cdots \mathrm{N}_{(4 \mathrm{~A})}$ & & 218.0 & & & 215.9 & & & & & \\
\hline & & & & & & B97D & & & & \\
\hline$\Delta \mathrm{N}_{(4 \mathrm{~A})}-\mathrm{H}$ & 0.7 & 1.0 & 0.4 & 0.6 & 0.7 & 0.5 & $\Delta \mathrm{C}_{(2 \mathrm{C})}-\mathrm{H}$ & -0.5 & -0.5 & -0.6 \\
\hline & & & 0.4 & & 0.5 & 0.5 & & & & \\
\hline $\mathrm{N}_{(4 \mathrm{~A})}-\mathrm{H} \cdots \mathrm{N}_{(4 \mathrm{~B} / 4 \mathrm{D})}$ & 218.4 & 211.9 & 227.9 & 221.2 & 217.4 & 225.3 & $\mathrm{C}_{(2 \mathrm{C})}-\mathrm{H} \cdots \mathrm{N}_{(\mathrm{A})}$ & 266.2 & 258.3 & 256.5 \\
\hline & & & 234.0 & & 222.6 & 226.4 & & & & \\
\hline $\mathrm{N}_{(4 \mathrm{C})}-\mathrm{H} \cdots \mathrm{N}_{(4 \mathrm{~A})}$ & & 210.1 & & & 210.6 & & & & & \\
\hline & & & & & & wB97X & & & & \\
\hline$\Delta \mathrm{N}_{(4 \mathrm{~A})}-\mathrm{H}$ & 0.7 & 1.0 & 0.6 & 0.7 & 0.8 & 0.6 & $\Delta \mathrm{C}_{(2 \mathrm{C})}-\mathrm{H}$ & -0.3 & -0.4 & -0.4 \\
\hline & & 0.0 & 0.6 & & 0.6 & 0.6 & & & & \\
\hline $\mathrm{N}_{(4 \mathrm{~A})}-\mathrm{H} \cdots \mathrm{N}_{(4 \mathrm{~B} / 4 \mathrm{D})}$ & 217.9 & 210.6 & 223.9 & 216.7 & 215.6 & 222.2 & $\mathrm{C}_{(2 \mathrm{C})}-\mathrm{H} \cdots \mathrm{N}_{(\mathrm{A})}$ & 268.5 & 254.8 & 252.7 \\
\hline & & & 225.0 & & 223.3 & 221.3 & & & & \\
\hline $\mathrm{N}_{(4 \mathrm{C})}-\mathrm{H} \cdots \mathrm{N}_{(4 \mathrm{~A})}$ & & 210.0 & & & 214.0 & & & & & \\
\hline
\end{tabular}

Referring to the variation of the intermolecular distances $(\mathrm{H} \cdots \mathrm{N})$, and assuming the cluster interconversion processes $\mathrm{O} 2 \mathrm{a} \rightarrow \mathrm{O} 3 \mathrm{a} \rightarrow \mathrm{O} 4 \mathrm{a}$ and $\mathrm{O} 2 \mathrm{a} \rightarrow \mathrm{O} 3 \mathrm{~b} \rightarrow \mathrm{O} 4 \mathrm{~b}$, it is found that the general trends oppose the ones observed for the variation of the $\mathrm{N}-\mathrm{H}$ covalent bond. The lengthening of the $\mathrm{N}-\mathrm{H}$ bonds observed in the formation of $\mathbf{O 3 a}$ and $\mathbf{O} 4 \mathbf{b}$ is accomplished by a decrease of the corresponding $\mathrm{H} \cdots \mathrm{N}$ distances. In turn, the strengthening of the $\mathrm{N}-\mathrm{H}$ bonds observed in the formation of $\mathbf{O} 3 \mathbf{b}$ and $\mathbf{O} 4 \mathbf{a}$ is coupled with a shortening of the corresponding $\mathrm{H} \cdots \mathrm{N}$ distances. A similar straightforward correlation is, unfortunately, not observed when the $\mathrm{C}-\mathrm{H} \cdots \mathrm{N}$ intermolecular interactions are analysed.
In these cases, the direction of the variations is dependent on the type of DFT used and if BSSE correction is performed. However, assuming a higher accuracy of the CP-corrected B97D and $w B 97 X D$ results, it is expectable that incrementing the involvement of the $\mathrm{NH}_{2}$-group in hydrogen bonds $(\mathbf{O} 2 \mathbf{b}$ $\rightarrow \mathrm{O} 3 \mathrm{c} \rightarrow \mathrm{O} 4 \mathrm{~b}$ ) promotes a progressive strengthening of the $\mathrm{C}-\mathrm{H} \cdots \mathrm{N}$ intermolecular interaction, as judged by the $\mathrm{H} \cdots \mathrm{N}$ distance reduction pattern predicted.

3.3. Vibrational Analysis. The assignment of the vibrational spectra of pure liquid iPram was recently reviewed on 
TABLE 2: CP-corrected vibrational frequency shifts predicted with B97D functional for the $\mathrm{NH}_{2}$ and $\mathrm{C}_{(2)}-\mathrm{H}$ molecular groups. Cluster nomenclature according to Figure 1.

\begin{tabular}{|c|c|c|c|c|c|c|c|c|c|c|}
\hline \multirow{2}{*}{ M } & \multirow{2}{*}{ Mode $^{a}$} & \multicolumn{2}{|c|}{ O2a } & \multicolumn{2}{|c|}{ O2b } & \multirow{2}{*}{ O3a } & \multirow[t]{2}{*}{ O3b } & \multirow{2}{*}{$\begin{array}{c}\text { O3c } \\
\text { Unit A }\end{array}$} & \multirow[t]{2}{*}{ O4a } & \multirow[t]{2}{*}{ O4b } \\
\hline & & Unit A & Unit B & Unit A & Unit $\mathbf{C}$ & & & & & \\
\hline 3457 & $v_{\mathrm{as}} \mathrm{NH}_{2}$ & -41 & 3 & 2 & -6 & -36 & -73 & -32 & -115 & -91 \\
\hline 3358 & $v_{\mathrm{s}} \mathrm{NH}_{2}$ & -87 & 2 & 2 & -6 & -130 & -69 & -81 & -112 & -87 \\
\hline 1665 & $\delta \mathrm{NH}_{2}$ & 33 & -4 & 0 & 0 & 36 & 47 & 31 & 53 & 49 \\
\hline 1250 & $\mathrm{tNH}_{2}$ & 21 & 0 & 1 & 12 & 26 & 30 & 14 & 44 & 33 \\
\hline 858 & $\omega \mathrm{NH}_{2}$ & 57 & 16 & 5 & 10 & 71 & 66 & 48 & 76 & 71 \\
\hline 308 & $\tau \mathrm{NH}_{2}$ & 139 & 19 & -3 & -1 & 219 & 250 & 127 & 314 & 273 \\
\hline 2845 & $v \mathrm{C}_{(2)}-\mathrm{H}$ & -16 & 20 & 6 & 68 & -3 & -25 & -8 & -16 & -22 \\
\hline 1370 & $\beta \mathrm{C}_{(2)}-\mathrm{H}$ & 0 & 1 & 1 & 4 & 3 & -2 & -2 & 4 & -2 \\
\hline 1353 & $\gamma \mathrm{C}_{(2)}-\mathrm{H}$ & 3 & 2 & 2 & 25 & 3 & 1 & 3 & 3 & 3 \\
\hline
\end{tabular}

a $\nu=$ stretching, $\delta=$ deformation, $\mathrm{t}=$ twisting, $\omega=$ wagging, $\tau=$ torsion, $\beta=$ in-plane deformation and $\gamma=$ out-of-plane deformation.

the basis of quantum chemical calculations performed for the isolated molecule (monomer, M) [35], using different DFT approaches. As stated there, some of the predicted vibrational modes, namely, those related to the $\mathrm{NH}_{2}-$ and $\mathrm{C}_{(2)}-\mathrm{H}$ groups, were found to be significantly shifted relative to the corresponding experimental value. This observation naturally raised the question to what extent the involvement of those molecular groups in intermolecular interactions, expected to occur in the condensed phase, is responsible for these deviations.

Table 2 presents the $\mathrm{CP}$-corrected deviations, relative to the monomer, predicted for the fundamental vibrational modes ascribed to the $\mathrm{NH}_{2}$ and $\mathrm{C}_{(2)}-\mathrm{H}$ groups of iPram in the different clusters considered. The CP-uncorrected and CPcorrected values obtained when using all the DFT methods are compared in Tables S2-S7 of the Supplementary Material. The present analysis is limited to the nine vibrational modes related to the $\mathrm{NH}_{2}$ and $\mathrm{C}_{(2)}-\mathrm{H}$ groups as they are expectedly the most affected ones, due to their direct involvement in the intermolecular interactions. In the case of the dimeric species, the frequency shifts calculated for both iPram units (A and either $\mathbf{B}$ or $\mathbf{C}$ ) are presented. Referring to the higher species, only the shifts observed for unit $\mathbf{A}$ are targeted as gauging the effects of $\mathrm{H}$-bond cooperativity on the predicted vibrational frequencies is aimed.

The results show that neither $\mathrm{CP}$ correction nor changing DFT (Tables S2-S7) affects the general trends observed for the vibrational frequency shifts promoted by the intermolecular interactions. The most significant deviations are definitely observed for the amine related vibrational modes, when the $\mathrm{NH}_{2}$-group participates in one of the $\mathrm{H}$-bonds as a donor. When the amine group acts only as an acceptor (unit $\mathbf{B}$ in $\mathbf{O 2} \mathbf{a}$ and both units, $\mathbf{A}$ and $\mathbf{C}$, in $\mathbf{O} 2 \mathbf{b}$ ), the vibrational mode deviations promoted are almost negligible.

Among the six vibrational modes related to the $\mathrm{NH}_{2}$ group, the two stretching modes (symmetric, $v_{s} \mathrm{NH}_{2}$, and antisymmetric, $\left.v_{\text {as }} \mathrm{NH}_{2}\right)$ and the torsional mode $\left(\tau \mathrm{NH}_{2}\right)$ are by far the most affected ones (Table 2). The three $\mathrm{NH}_{2}$ deformation modes (scissoring, $\delta \mathrm{NH}_{2}$, twisting, $\mathrm{tNH}_{2}$, and wagging, $\omega \mathrm{NH}_{2}$ ) denote blueshiftings that are comparatively very slight. Both $v_{\mathrm{s}} \mathrm{NH}_{2}$ and $v_{\mathrm{as}} \mathrm{NH}_{2}$ modes are significantly redshifted upon establishment of the $\mathrm{N}-\mathrm{H} \cdots \mathrm{N}$ interactions, in line with results reported by others $[6,8,10]$. The largest redshift of the $v_{\mathrm{s}} \mathrm{NH}_{2}$ mode is observed when the amine group acts simultaneously as donor and acceptor in the overall $\mathrm{H}$-bonding pattern $(\mathbf{O 3 a}, \mathbf{O} \mathbf{c}$, and $\mathbf{O 4 a})$. In what concerns the $v_{\text {as }} \mathrm{NH}_{2}$ mode, the maximum shifting is observed when the amine group $\mathrm{H}$-bonding capacity is achieved. In both cases, the magnitude of the shifts are attenuated when the acceptor character of the amine group is given in a $\mathrm{C}-\mathrm{H} \cdots \mathrm{N}$ interaction.

Referring to the effect of hydrogen bonding cooperativity, the results suggest that the effects promoted on the two amine stretching modes oppose each other. In the case of the $v_{\mathrm{s}} \mathrm{NH}_{2}$ mode, $\mathrm{H}$-bond cooperativity tends to enhance the redshifting degree (e.g., O2a $\rightarrow \mathbf{O 3 a}$ and $\mathbf{O 2 a} \rightarrow \mathbf{O} 3 \mathbf{c}$ ), an effect that is opposed by the increase of the amine group involvement as an $\mathrm{H}$-bond donor (e.g., O2a $\rightarrow \mathbf{O} 3 \mathbf{b}, \mathrm{O} 3 \mathbf{a} \rightarrow \mathrm{O} 4 \mathrm{a}$, and $\mathrm{O} 3 \mathbf{c} \rightarrow$ O4b). The variation trends observed for the $v_{\mathrm{as}} \mathrm{NH}_{2}$ mode are, in every way, opposite to those predicted for the $\nu_{\mathrm{s}} \mathrm{NH}_{2}$ mode.

Analysis of the effects of amine involvement in hydrogen bonding on the prediction of the $\tau \mathrm{NH}_{2}$ vibrational mode requires a more profound discussion. In the prior publication [35], difficulties were encountered in ascribing the $\tau \mathrm{NH}_{2}$ mode. Durig et al. [36] ascribed the $\tau \mathrm{NH}_{2}$ mode of iPram, in the trans-form, to a weak spectral feature observed around $267 \mathrm{~cm}^{-1}$ in the infrared gas-phase spectrum. This assignment is supported by the calculations performed for the monomeric form of iPram, which predicted the $\tau \mathrm{NH}_{2}$ mode at about $300 \mathrm{~cm}^{-1}$ (Tables S2-S7). However, neither Durig et al. [36] nor the more recent work of Padrào et al. [35] was able to ascribe this mode to a particular spectral feature of either infrared or Raman spectra of liquid iPram.

The present predictions for the $\tau \mathrm{NH}_{2}$ mode of iPram suggest that the $\mathrm{H}$-bond involvement of the amine group generally leads to a significant blueshifting of the $\tau \mathrm{NH}_{2}$ mode. The only requirement is that the amine group participates as a donor in at least one of the intermolecular interactions it is involved in. Incrementing the involvement of the $\mathrm{NH}_{2}-$ group in $\mathrm{N}-\mathrm{H} \cdots \mathrm{N}$ interactions (e.g., O2a $\rightarrow \mathbf{O} 3 \mathbf{a}, \mathbf{O} 2 \mathbf{a} \rightarrow$ $\mathbf{O} 3 \mathbf{b}$, and $\mathbf{O 3 a} \rightarrow \mathbf{O} 4 \mathbf{a}$ ) enhances the magnitude of the $\tau \mathrm{NH}_{2}$ 
blueshifting. Similar effects have been reported for other amine-containing systems such as polyamines. Marques et al. [37] found that the involvement of the amine group in hydrogen bonding shifts the $\tau \mathrm{NH}_{2}$ mode upwards by more than $100 \mathrm{~cm}^{-1}$. Even more pronounced $\tau \mathrm{NH}_{2}$ shiftings were predicted by Amado et al. [38] in the case of solid ethylenediamine dihydrochloride, where strong $\mathrm{N}-\mathrm{H} \cdots \mathrm{Cl}$ interactions promoted deviations up to $300 \mathrm{~cm}^{-1}$.

These observations naturally highlight the need to review the assignment of $\tau \mathrm{NH}_{2}$ mode in the spectrum of condensed iPram. Thus, taking into account the magnitude of the shifts predicted to occur upon the establishment of the $\mathrm{N}-\mathrm{H} \cdots \mathrm{X}$ interactions, the $\tau \mathrm{NH}_{2}$ mode is most likely shifted to the $450-590 \mathrm{~cm}^{-1}$ spectral region. Being so, the $\tau \mathrm{NH}_{2}$ mode becomes overlapped with the in-plane and out-of-plane $\mathrm{C}_{(2)}-\mathrm{NH}_{2}$ deformation modes $\left(\beta \mathrm{C}_{(2)}-\mathrm{NH}_{2}\right.$ and $\gamma \mathrm{C}_{(2)}-\mathrm{NH}_{2}$, resp.), which are predicted to occur in the $400-500 \mathrm{~cm}^{-1}$ spectral region (results not shown).

Finally, regarding the effect of hydrogen bonding on the three vibrational modes related to the $\mathrm{C}_{(2)}-\mathrm{H}$ group, it is found that only the stretching mode $\left(\nu \mathrm{C}_{(2)}-\mathrm{H}\right)$ seems to be significantly affected. The direction of the $\nu \mathrm{C}_{(2)}-\mathrm{H}$ shifts is found to be dependent on the kind of $\mathrm{H}$-bond involvement of the amine group in the same iPram unit. In the cases where the amine group acts as an $\mathrm{H}$-bond donor (e.g., unit $\mathbf{A}$ in $\mathbf{O} 2 \mathbf{a}, \mathbf{O} 3 \mathbf{b}$, and $\mathbf{O} 4 \mathbf{b}$ ) the $\nu \mathrm{C}_{(2)}-\mathrm{H}$ mode is predicted to be redshifted. But when the amine group is involved as an acceptor (e.g., unit $\mathbf{B}$ in $\mathbf{O 2 a}$ and unit $\mathbf{C}$ in $\mathbf{O 2 b}$ ), the $\nu \mathrm{C}_{(2)}{ }^{-}$ $\mathrm{H}$ denotes a considerable blueshifting. This later effect $(\nu \mathrm{C}-$ $\mathrm{H}$ blueshifting) has been observed, both theoretically and experimentally, for several other molecular systems, and has attracted great interest over the years [39-46].

The $\mathrm{C}-\mathrm{H}$ stretching bands ascribed to carbon-hydrogen bonds which, as the $\mathrm{C}_{(2)}-\mathrm{H}$ of iPram, are anticoplanar to nitrogen lone pairs have been named as Bohlmann bands [47]. The Bohlmann effect has been correlated with a delocalization of the nitrogen lone pair, $\operatorname{Lp}(\mathrm{N})$, onto the $\alpha$-hydrogen bond lying in a relative trans-orientation. This effect leads to a weakening of the $\mathrm{C}-\mathrm{H}$ bond and, hence, to a lowering (redshift) of the $\nu \mathrm{C}-\mathrm{H}$ mode. This effect has been widely reported in the literature [31-33, 47] and explains, at least in part, the lowering of $115 \mathrm{~cm}^{-1}$ predicted for the $\nu \mathrm{C}_{(2)}-\mathrm{H}$ mode of iPram on changing from the gauche- to the trans-form [35].

The present results show that formation of molecular clusters of iPram may enhance or attenuate the Bohlmann effect, depending on the kind and number of intermolecular interactions holding up the aggregate. Regarding the dimeric forms, it is found that either the direct $\mathrm{H}$-bond involvement of the $\mathrm{C}_{(2)}-\mathrm{H}$ group (as a donor; unit $\mathbf{C}$ in $\mathbf{O} 2 \mathbf{b}$ ) or the involvement of the amine group as an $\mathrm{H}$-bond acceptor (unit $\mathbf{B}$ in $\mathbf{O} 2 \mathbf{a}$ and unit $\mathbf{A}$ in $\mathbf{O} 2 \mathbf{b}$ ) leads to an attenuation of the Bohlmann effect. In other words, the $\nu \mathrm{C}_{(2)}-\mathrm{H}$ mode is blueshifted. On the contrary, in the cases where the amine group acts as the $\mathrm{H}$-bond donor (unit $\mathbf{A}$ in $\mathbf{O 2 a}$ ), the Bohlmann effect is enhanced and the $\nu \mathrm{C}_{(2)}-\mathrm{H}$ mode is redshifted. The overall effect in the higher cluster forms may be seen as a balance of the individual effects observed for dimeric forms. Increasing the donor involvement of the
TABLE 3: Comparison of the B97D CP-corrected frequency shifts predicted by the PiMM and the full cluster approaches for the $\mathrm{NH}_{2}$ and $\mathrm{C}_{(2)}-\mathrm{H}$ related vibrational modes. Only the vibrational shifts for the O3a and O4a clusters are presented (for the other iPram clusters see Table S8 of the Supplementary Material).

\begin{tabular}{lcccc}
\hline Mode $^{\mathrm{a}}$ & \multicolumn{2}{c}{ O3a } & \multicolumn{2}{c}{ O4a } \\
& PiMM & Full $^{\mathrm{b}}$ & PiMM & Full $^{\mathrm{b}}$ \\
\hline$\nu_{\mathrm{as}} \mathrm{NH}_{2}$ & -38 & -36 & -79 & -115 \\
$\nu_{\mathrm{s}} \mathrm{NH}_{2}$ & -85 & -130 & -172 & -112 \\
$\delta \mathrm{NH}_{2}$ & 29 & 36 & 62 & 53 \\
$\mathrm{tNH}_{2}$ & 21 & 26 & 42 & 44 \\
$\omega \mathrm{NH}_{2}$ & 73 & 71 & 130 & 76 \\
$\tau \mathrm{NH}_{2}$ & 158 & 219 & 297 & 314 \\
$\nu \mathrm{C}_{(2)}-\mathrm{H}$ & 4 & -3 & -12 & -16 \\
$\beta \mathrm{C}_{(2)}-\mathrm{H}$ & 1 & 3 & 1 & 4 \\
$\gamma \mathrm{C}_{(2)}-\mathrm{H}$ & 5 & 3 & 8 & 3 \\
\hline
\end{tabular}

${ }^{\mathrm{a}} \nu=$ stretching, $\delta=$ deformation, $\mathrm{t}=$ twisting, $\omega=$ wagging, $\tau=$ torsion, $\beta=$ in-plane deformation and $\gamma=$ out-of-plane deformation.

${ }^{\mathrm{b}}$ Full-cluster approach.

amine group in the $\mathrm{H}$-bonding pattern (e.g., unit $\mathbf{A}$ in $\mathbf{O 2 a} \rightarrow$ $\mathbf{O} 2 \mathbf{a} \rightarrow \mathbf{O} 4 \mathbf{a})$ clearly enhances the Bohlmann effect with the $\nu \mathrm{C}_{(2)}-\mathrm{H}$ mode being progressively more redshifted.

3.4. Evaluation of the PiMM Methodology. Aiming at evaluating the effect of the short-range interactions on the theoretical predictions of the vibrational spectra of condensed materials, some of the authors developed the Pairs in Molecular Materials (PiMM) methodology [48]. This approach assumes that the effects of the individual intermolecular interactions, in which a given molecular entity is involved in, are pairwise additive. Application of the method has been used with success in the assignment of the vibrational spectra of several solid pharmaceutical drugs known to present polymorphic forms [48-51]. However, that accuracy evaluation was conditioned by the fact that, according to the X-ray data available for those drugs, none of the systems presented a molecular group involved in multiple hydrogen bonds. In view of fulfilling this gap, the present section intends to gauge the errors associated with neglecting the effect of cooperativity between multiple $\mathrm{H}$-bonds centered at the same molecular fragment, in the present case the $\mathrm{NH}_{2}$ group of iPram.

Table 3 compares the shifts predicted for the $\mathrm{NH}_{2}$ and $\mathrm{C}_{(2)}-\mathrm{H}$ related vibrational modes when applying either the PiMM or the fullcluster approaches to the B97D CP-corrected results. The comparison presented in Table 3 is restricted to the two clusters found to present the highest stability and CEHB, namely, O3a and O4a. Listing of the frequency shifts predicted for the PiMM approach for all clusters (CPuncorrected and CP-corrected) is found in Table S8 of the Supplementary Material. As in Table 2, only the deviations predicted for unit $\mathbf{A}$ in each cluster are presented.

Recall that, within the PiMM approach, the effects of the different intermolecular interactions on the vibrational modes of a given molecular group are considered independent and additive [48]. Thus, considering cluster O3a, the 
tabulated deviations correspond to the sum of the deviations predicted for units A and B of cluster O2a. In the case of the O4b cluster, on the other hand, the values are the sum of twice the deviations observed for unit A of O2a and the deviations in unit $\mathbf{A}$ of $\mathbf{O} 2 \mathbf{b}$.

Comparison of the deviations predicted for the different vibrational modes by either applying the PiMM methodology or the full cluster geometry optimization method (Table S8 versus Table 2) shows that, in general, the shifting directions are the same. The only exception that is worth to be mentioned refers to $\delta \mathrm{NH}_{2}$ vibrational mode, in all clusters excepting $\mathbf{O} \mathbf{3 b}$.

The same consistency is, however, not observed with respect to the magnitude of the deviations envisaged. In some cases, the deviations provided by the PiMM method are much higher than those obtained when considering the overall optimized molecular cluster. The deviations envisaged by PiMM for the $\nu_{s} \mathrm{NH}_{2}$ and $\omega \mathrm{NH}_{2}$ vibrational modes in $\mathbf{O 3} \mathbf{b}$, $\mathbf{O} 4 \mathbf{a}$, and $\mathbf{O} 4 \mathbf{b}$, for example, are well beyond those provided by the method of full cluster optimized. The opposing effect is, however, observed when the $v_{\text {as }} \mathrm{NH}_{2}$ and $\tau \mathrm{NH}_{2}$ modes in O3a and O4a are regarded. In these cases, the PiMM deviations are significantly underestimated relative to those provided by the full cluster optimization method.

On the whole, these observations suggest that the PiMM method is a quite effective methodology for predicting whose vibrational modes are overdeviated due to the establishment of intermolecular interactions. It is also effective in predicting the direction of the deviations (blue- or redshifting). However, as expected, the effectiveness of the method in predicting the magnitude of the deviations is strongly affected by neglecting the potential effects of cooperativity among multiple hydrogen bonds.

\section{Conclusions}

In the present work, calculations, using different DFT methods, were performed to infer on the effects of intermolecular interactions on the prediction of several molecular properties of isopropylamine. From a practicable point of view, B97D/6$31 \mathrm{G}^{*}$ and $\mathrm{wB} 97 \mathrm{XD} / 6-31 \mathrm{G}^{*}$ theory levels were found to present the best balance between the computational costs and accuracy. As opposed to the conventional DFT methods, both dispersion corrected DFTs were able to stabilize the weak $\mathrm{C}-\mathrm{H} \cdots \mathrm{N}$ despite the smallness of the basis set. The conventional DFT methods were only able to describe that type of intermolecular interactions when a significant improvement of the basis set is performed, which involves a drastic increase of the computational requirements.

With no surprise, the results showed that the overall cluster stability increases with oligomer size. However, the stability enhancement observed is not always coupled with cooperativity effects between multiple hydrogen bonds. The energetic and structural evaluation performed showed that achievement of maximal hydrogen bond cooperativity requires a $\mathrm{d}$-a hydrogen bonding involvement of the amine group. Involvement of the $\mathrm{NH}_{2}$-group in a $\mathrm{d}$ - $\mathrm{d} \mathrm{H}$-bond pattern tends to break $\mathrm{H}$-bond cooperativity.
Regarding the prediction of the vibrational frequencies of iPram, it was found that establishment of intermolecular interactions affects particularly the amine related modes. One of the most affected modes is the $\tau \mathrm{NH}_{2}$. This mode is significantly blueshifted upon the establishment of intermolecular interactions that involve the amine group as an $\mathrm{H}$-bond donor. As a consequence, the $\tau \mathrm{NH}_{2}$ mode of liquid iPram turns overlapped with the with the $\beta \mathrm{C}_{(2)}-\mathrm{NH}_{2}$ and $\gamma \mathrm{C}_{(2)}{ }^{-}$ $\mathrm{NH}_{2}$ modes.

The Bohlmann band $\left(\nu \mathrm{C}_{(2)}-\mathrm{H}\right)$ of iPram was also found to be sensitive to the hydrogen bonding pattern characterizing the molecular cluster. The results clearly showed that both direct involvement of the $\mathrm{C}_{(2)}-\mathrm{H}$ group and amine group involvement as an acceptor in the hydrogen bonding pattern tend to an attenuation of the Bohlmann effect (i.e., promote a blueshift of the $\nu \mathrm{C}_{(2)}-\mathrm{H}$ mode). The involvement of the amine group as an $\mathrm{H}$-bond donor, on the other hand, tends to enhance the Bohlmann effect (i.e., promote a redshift of the $\nu \mathrm{C}_{(2)}-\mathrm{H}$ mode). The overall effect observed on the $\nu \mathrm{C}_{(2)}-\mathrm{H}$ mode as the iPram hydrogen bonding involvement enhances corresponds to a balance between those two lines of evidence taking into account the type and number of intermolecular interactions holding the cluster geometry.

Finally, for the evaluation of the effects of cooperativity on the reliability of the PiMM method [48] for predicting the vibrational frequencies, it was found that the methodology gives good evidences on the sign of the frequency deviations upon establishment of the intermolecular interactions. However, the magnitudes of the individual shifts are not always well predicted by the PiMM method, particularly when the overall $\mathrm{H}$-bonding pattern allows strong cooperativity effects between multiple hydrogen bonds. Some of the vibrational modes evaluated were found to be more sensitive than others. Among the vibrational modes whose deviations were more poorly predicted by the pairwise PiMM approach are undoubtedly the $\omega \mathrm{NH}_{2}, \tau \mathrm{NH}_{2}, v_{\mathrm{s}} \mathrm{NH}_{2}$, and $\nu_{\text {as }} \mathrm{NH}_{2}$ modes.

\section{Supporting Information}

Listing of the CP-uncorrected and CP-corrected vibrational frequencies predicted for the $\mathrm{NH}_{2}$ and $\mathrm{C}_{(2)}-\mathrm{H}$ modes when using each of the different DFT methods tested can be found in the Supporting Information linked to the online version of the paper.

\section{Acknowledgment}

The authors acknowledge the financial support from the Portuguese Foundation for Science and Technology-Unidade de Química-Física Molecular (PEst-OE/QUI/UI0070/2011) and Laboratório Associado CICECO.

\section{References}

[1] G. A. Jeffrey, An Introduction to Hydrogen Bonding, Oxford University Press, New York, NY, USA, 1997.

[2] Y. Lu, Y. Wang, Z. Xu et al., "C-X $\cdots H$ contacts in biomolecular systems: how they contribute to protein-ligand binding affinity," 
The Journal of Physical Chemistry B, vol. 113, no. 37, pp. 1261512621, 2009.

[3] S. Melandri, “Union is strength': how weak hydrogen bonds become stronger," Physical Chemistry Chemical Physics, vol. 13, no. 31, pp. 13901-13911, 2011.

[4] N. Rawat and P. Biswas, "Shape, flexibility and packing of proteins and nucleic acids in complexes," Physical Chemistry Chemical Physics, vol. 13, no. 20, pp. 9632-9643, 2011.

[5] T. Wyttenbach and M. T. Bowers, "Hydration of biomolecules," Chemical Physics Letters, vol. 480, no. 1-3, pp. 1-16, 2009.

[6] E. M. Cabaleiro-Lago and M. A. Ríos, "Ab initio study of interactions in methylamine clusters. The significance of cooperative effects," Journal of Chemical Physics, vol. 112, no. 5, pp. 21552163, 2000.

[7] E. M. Cabaleiro-Lago and M. A. Ríos, "An ab initio study of the interaction in dimethylamine dimer and trimer," Journal of Chemical Physics, vol. 113, no. 21, pp. 9523-9531, 2000.

[8] M. F. de Carvalho, R. A. Mosquera, and R. Rivelino, "A density functional theory study of the hydrogen bond interactions in glycine dimers," Chemical Physics Letters, vol. 445, no. 4-6, pp. 117-124, 2007.

[9] Q. Li, X. An, B. Gong, and J. Cheng, "Spectroscopic and theoretical evidence for the cooperativity between red-shift hydrogen bond and blue-shift hydrogen bond in DMSO aqueous solutions," Spectrochimica Acta A, vol. 69, no. 1, pp. 211-215, 2008.

[10] A. S. Mahadevi, Y. I. Neela, and G. N. Sastry, "A theoretical study on structural, spectroscopic and energetic properties of acetamide clusters $\left[\mathrm{CH}_{3} \mathrm{CONH}_{2}\right](n=1-15)$, , Physical Chemistry Chemical Physics, vol. 13, no. 33, pp. 15211-15220, 2011.

[11] R. D. Parra, M. Furukawa, B. Gong, and X. C. Zeng, "Energetics and cooperativity in three-center hydrogen bonding interactions. I. Diacetamide- $\mathrm{X}$ dimers $\left(\mathrm{X}=\mathrm{HCN}, \mathrm{CH}_{3} \mathrm{OH}\right)$," Journal of Chemical Physics, vol. 115, no. 13, pp. 6030-6035, 2001.

[12] M. J. Frisch, G. W. Trucks, H. B. Schlegel et al., Gaussian 09, Revision A.02, Gaussian 09, Revision A.02, Gaussian, Inc., Wallingford, Conn, USA, 2009.

[13] V. Barone, M. Biczysko, and M. Pavone, "The role of dispersion correction to DFT for modelling weakly bound molecular complexes in the ground and excited electronic states," Chemical Physics, vol. 346, no. 1-3, pp. 247-256, 2008.

[14] I. Dabkowska, P. Jurečka, and P. Hobza, "On geometries of stacked and $\mathrm{H}$-bonded nucleic acid base pairs determined at various DFT, MP2, and CCSD(T) levels up to the $\operatorname{CCSD}(\mathrm{T}) /$ complete basis set limit level," The Journal of Chemical Physics, vol. 122, no. 20, Article ID 204322, 9 pages, 2005.

[15] S. Grimme, "Semiempirical GGA-type density functional constructed with a long-range dispersion correction," Journal of Computational Chemistry, vol. 27, no. 15, pp. 1787-1799, 2006.

[16] J. Ireta, J. Neugebauer, and M. Scheffler, "On the accuracy of DFT for describing hydrogen bonds: dependence on the bond directionality," The Journal of Physical Chemistry A, vol. 108, no. 26, pp. 5692-5698, 2004.

[17] R. Peverati, M. Macrina, and K. K. Baldridge, "Assessment of DFT and DFT-D for potential energy surfaces of rare gas trimers-implementation and analysis of functionals and extrapolation procedures," Journal of Chemical Theory and Computation, vol. 6, no. 7, pp. 1951-1965, 2010.

[18] A. M. Amado, S. M. Fiuza, L. A. E. Batista de Carvalho, and P. J. A. Ribeiro-Claro, "On the effects of changing Gaussian program version and SCRF defining parameters: Iisopropylamine as a case study," Bulletin of the Chemical Society of Japan, vol. 85, no. 9, pp. 962-975, 2012.

[19] 2011, http://www.gaussian.com/g_tech/g_ur/k_dft.htm.

[20] S. F. Boys and F. Bernardi, “The calculation of small molecular interactions by the differences of separate total energies. Some procedures with reduced errors," Molecular Physics, vol. 19, no. 4, pp. 553-566, 1970.

[21] L. F. Holroyd and T. van Mourik, "Insufficient description of dispersion in B3LYP and large basis set superposition errors in MP2 calculations can hide peptide conformers," Chemical Physics Letters, vol. 442, no. 1-3, pp. 42-46, 2007.

[22] Y.-G. Wang, "Examination of DFT and TDDFT methods II," The Journal of Physical Chemistry A, vol. 113, no. 41, pp. 10873-10879, 2009.

[23] I. A. W. Filot, A. R. A. Palmans, P. A. J. Hilbers, R. A. van Santen, E. A. Pidko, and T. F. A. de Greef, "Understanding cooperativity in hydrogen-bond-induced supramolecular polymerization: a density functional theory study," The Journal of Physical Chemistry B, vol. 114, no. 43, pp. 13667-13674, 2010.

[24] P. L. Huyskens, "Factors governing the influence of a first hydrogen bond on the formation of a second one by the same molecule or ion," Journal of the American Chemical Society, vol. 99, no. 8, pp. 2578-2582, 1977.

[25] M. P. Hodges, A. J. Stone, and S. S. Xantheas, "Contribution of many-body terms to the energy for small water clusters: a comparison of ab initio calculations and accurate model potentials," The Journal of Physical Chemistry A, vol. 101, no. 48, pp. 9163-9168, 1997.

[26] H. Kistenmacher, G. C. Lie, H. Popkie, and E. Clementi, "Study of the structure of molecular complexes. VI. Dimers and small clusters of water molecules in the Hartree-Fock approximation," The Journal of Chemical Physics, vol. 61, no. 2, pp. 546-561, 1974.

[27] A. Ebrahimi, H. Roohi, and S. Mostafa Habibi, "The characterization of stationary points in the potential energy surface of difluoromethane dimer," Journal of Molecular Structure: THEOCHEM, vol. 684, no. 1-3, pp. 87-93, 2004.

[28] J. Joseph and E. D. Jemmis, "Red-, blue-, or no-shift in hydrogen bonds: a unified explanation," Journal of the American Chemical Society, vol. 129, no. 15, pp. 4620-4632, 2007.

[29] A. Kovács, A. Szabó, D. Nemcsok, and I. Hargittai, "Blueshifting $\mathrm{C}-\mathrm{H} \cdots \mathrm{X},(\mathrm{X}=\mathrm{O}$, halogen $)$ hydrogen bonds in the dimers of formaldehyde derivatives," The Journal of Physical Chemistry A, vol. 106, no. 23, pp. 5671-5678, 2002.

[30] P.-P. Zhou and W.-Y. Qiu, "Red- and blue-shifted hydrogen bonds in the cis-trans noncyclic formic acid dimer," ChemPhysChem, vol. 10, no. 11, pp. 1847-1858, 2009.

[31] A. K. Chandra, S. Parveen, S. Das, and T. Zeegers-Huyskens, "Blue shifts of the $\mathrm{C}-\mathrm{H}$ stretching vibrations in hydrogenbonded and protonated trimethylamine. Effect of hyperconjugation on bond properties," Journal of Computational Chemistry, vol. 29, no. 9, pp. 1490-1496, 2008.

[32] A. K. Chandra, S. Parveen, and T. Zeegers-Huyskens, "Anomeric effects in the symmetrical and asymmetrical structures of triethylamine. Blue-shifts of the $\mathrm{C}-\mathrm{H}$ stretching vibrations in complexed and protonated triethylamine," The Journal of Physical Chemistry A, vol. 111, no. 36, pp. 8884-8891, 2007.

[33] K.-H. Chen, J.-H. Lii, Y. Fan, and N. L. Allinger, "Molecular mechanics (MM4) study of amines," Journal of Computational Chemistry, vol. 28, no. 15, pp. 2391-2412, 2007. 
[34] X. Li, L. Liu, and H. B. Schlegel, "On the physical origin of blue-shifted hydrogen bonds," Journal of the American Chemical Society, vol. 124, no. 32, pp. 9639-9647, 2002.

[35] S. Padrào, S. M. Fiuza, A. M. Amado, A. M. Amorim da Costa, and L. A. E. Batista de Carvalho, "Validation of the mPW1PW quantum chemical calculations for the vibrational study of organic molecules-re-assignment of the isopropylamine vibrational spectra," Journal of Physical Organic Chemistry, vol. 24, no. 2, pp. 110-121, 2011.

[36] J. R. Durig, G. A. Guirgis, and D. A. C. Compton, "Analysis of torsional spectra of molecules with two internal $\mathrm{C}_{3 v}$ rotors. 13 . Vibrational assignments, torsional potential functions, and gas phase thermodynamic functions of isopropylamine- $\mathrm{d}_{0}$ and $-\mathrm{d}_{2}$," The Journal of Physical Chemistry, vol. 83, no. 10, pp. 1313-1323, 1979.

[37] M. P. M. Marques, L. A. E. Batista de Carvalho, and J. Tomkinson, "Study of biogenic and $\alpha, \omega$-polyamines by combined inelastic neutron scattering and Raman spectroscopies and by ab initio molecular orbital calculations," The Journal of Physical Chemistry A, vol. 106, no. 11, pp. 2473-2482, 2002.

[38] A. M. Amado, J. C. Otero, M. P. M. Marques, and L. A. E. Batista de Carvalho, "Spectroscopic and theoretical studies on solid 1,2ethylenediamine dihydrochloride salt," ChemPhysChem, vol. 5, no. 12, pp. 1837-1847, 2004.

[39] E. Cubero, M. Orozco, P. Hobza, and F. J. Luque, "Hydrogen bond versus anti-hydrogen bond: a comparative analysis based on the electron density topology," The Journal of Physical Chemistry A, vol. 103, no. 32, pp. 6394-6401, 1999.

[40] P. Hobza, “The H-index unambiguously discriminates between hydrogen bonding and improper blue-shifting hydrogen bonding," Physical Chemistry Chemical Physics, vol. 3, no. 13, pp. 2555-2556, 2001.

[41] B. J. van der Veken, W. A. Herrebout, R. Szostak, D. N. Shchepkin, Z. Havlas, and P. Hobza, "The nature of improper, blueshifting hydrogen bonding verified experimentally," Journal of the American Chemical Society, vol.123, no. 49, pp. 12290-12293, 2001.

[42] W. Zierkiewicz, D. Michalska, Z. Havlas, and P. Hobza, "Study of the nature of improper blue-shifting hydrogen bonding and standard hydrogen bonding in the $\mathrm{X}_{3} \mathrm{CH} \cdots \mathrm{OH}_{2}$ and $\mathrm{XH} \cdots \mathrm{OH}_{2}$ complexes $(\mathrm{X}=\mathrm{F}, \mathrm{Cl}, \mathrm{Br}, \mathrm{I})$ : a correlated ab initio study," ChemPhysChem, vol. 3, no. 6, pp. 511-518, 2002.

[43] P. J. A. Ribeiro-Claro, L. Batista de Carvalho, and A. M. Amado, "Evidence of dimerization through C-H..O interactions in liquid 4-methoxybenzaldehyde from Raman spectra and $\mathrm{Ab}$ Initio calculations," Journal of Raman Spectroscopy, vol. 28, no. 11, pp. 867-872, 1997.

[44] P. J. A. Ribeiro-Claro, M. P. M. Marques, and A. M. Amado, "Experimental and theoretical evidence of $\mathrm{C}-\mathrm{H} \cdots \mathrm{O}$ hydrogen bonding in liquid 4-fluorobenzaldehyde," ChemPhysChem, vol. 3, no. 7, pp. 599-606, 2002.

[45] T. Steiner, E. B. Starikov, A. M. Amado, and J. J. C. Teixeira-Dias, "Weak hydrogen bonding. Part 2. The hydrogen bonding nature of short $\mathrm{C}-\mathrm{H} \cdots \pi$ contacts: cristallographic, spectroscopic and quantum-mechanical studies of some terminal alkynes," Journal of the Chemical Society, Perkin Transactions 2, no. 7, pp. 13211326, 1995.

[46] P. D. Vaz, M. Nolasco, N. Fonseca et al., "C-H... O hydrogen bonding in 4-phenyl-benzaldehyde: a comprehensive crystallographic, spectroscopic and computational study," Physical Chemistry Chemical Physics, vol. 7, no. 16, pp. 3027-3034, 2005.
[47] S. Wolfe, H. B. Schlegel, M. H. Whangbo, and F. Bernardi, "On the origin of the Bohlmann bands," Canadian Journal of Chemistry, vol. 52, no. 22, pp. 3787-3792, 1974.

[48] M. M. Nolasco, A. M. Amado, and P. J. A. Ribeiro-Claro, "Computationally-assisted approach to the vibrational spectra of molecular crystals: study of hydrogen-bonding and pseudopolymorphism," ChemPhysChem, vol. 7, no. 10, pp. 2150-2161, 2006.

[49] M. Sardo, A. M. Amado, and P. J. A. Ribeiro-Claro, "Hydrogen bonding in nitrofurantoin polymorphs: a computation-assisted spectroscopic study," Journal of Raman Spectroscopy, vol. 40, no. 12, pp. 1956-1965, 2009.

[50] M. M. Nolasco, A. M. Amado, and P. J. A. Ribeiro-Claro, "Effect of hydrogen bonding in the vibrational spectra of transcinnamic acid," Journal of Raman Spectroscopy, vol. 40, no. 4, pp. 394-400, 2009.

[51] M. M. Nolasco, A. M. Amado, and P. J. A. Ribeiro-Claro, "Insights into phase stability of anhydrous/hydrate systems: a Raman-based methodology," Journal of Raman Spectroscopy, vol. 41, no. 3, pp. 340-349, 2010. 

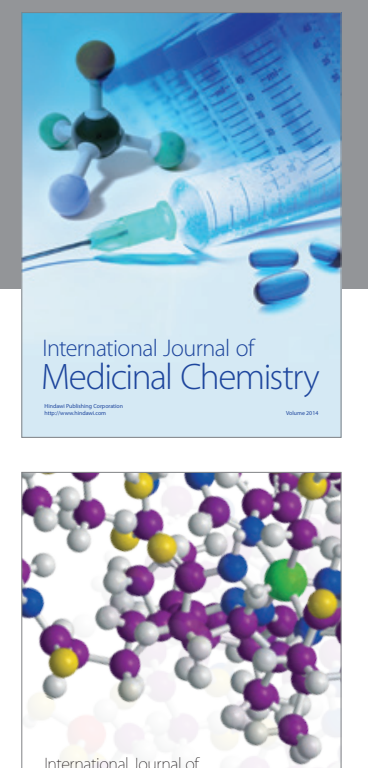

\section{Carbohydrate} Chemistry

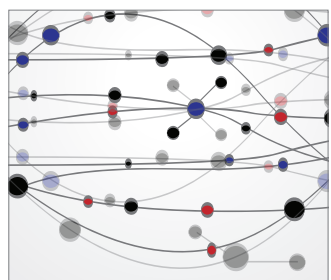

The Scientific World Journal
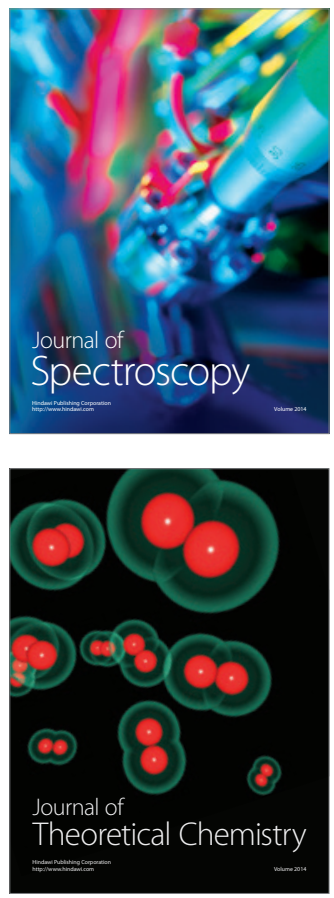
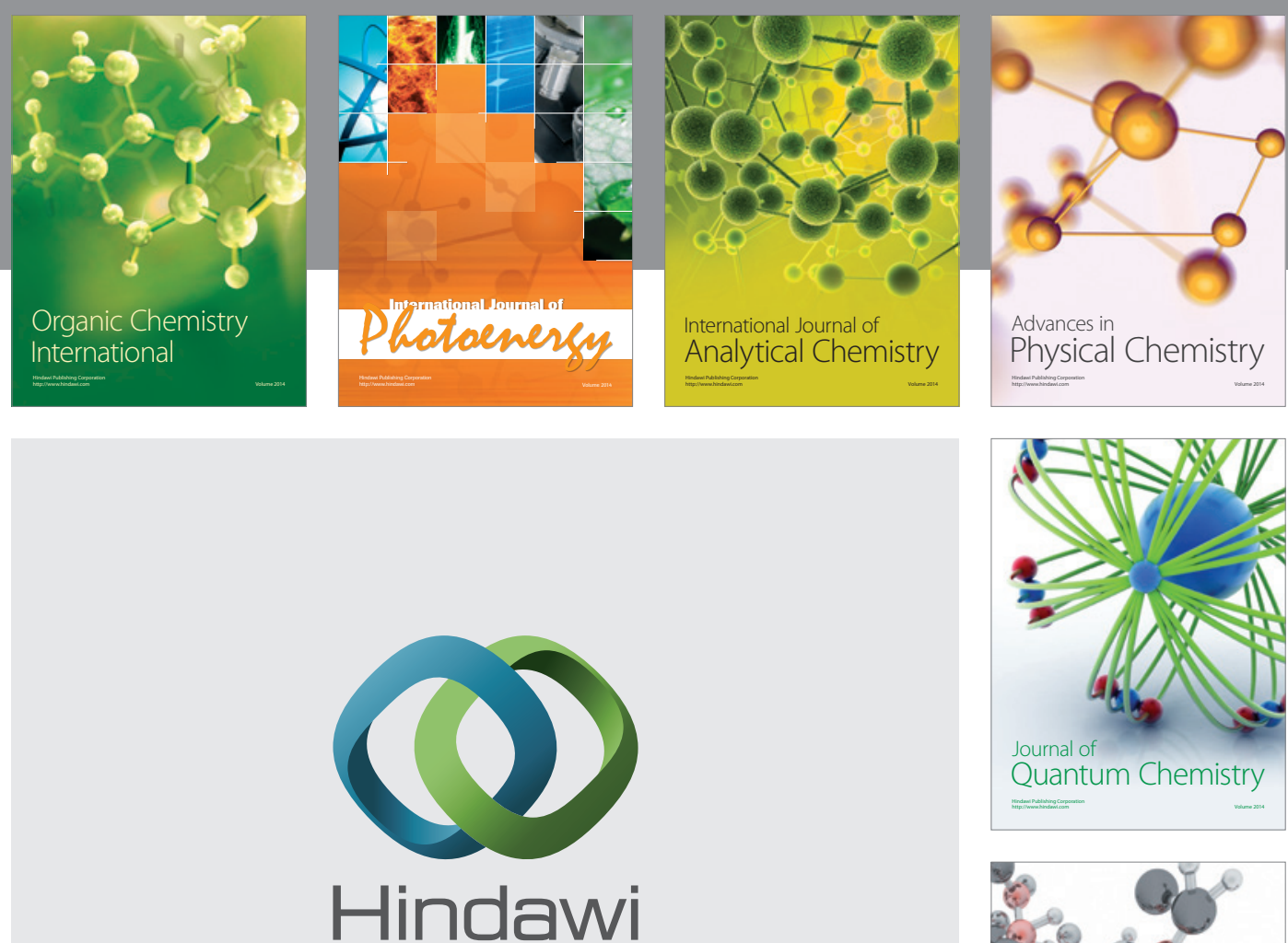

Submit your manuscripts at

http://www.hindawi.com

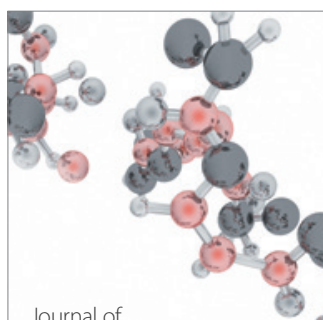

Analytical Methods

in Chemistry

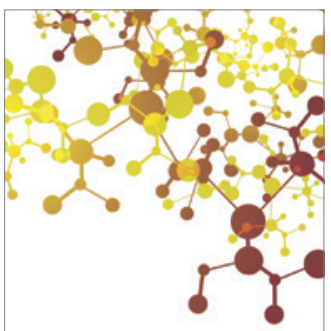

Journal of

Applied Chemistry

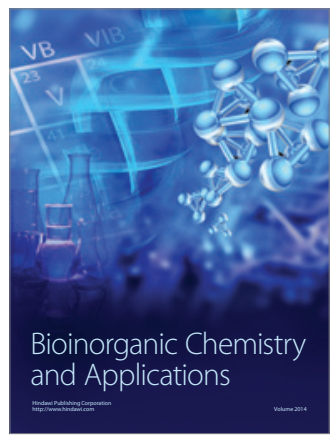

Inorganic Chemistry
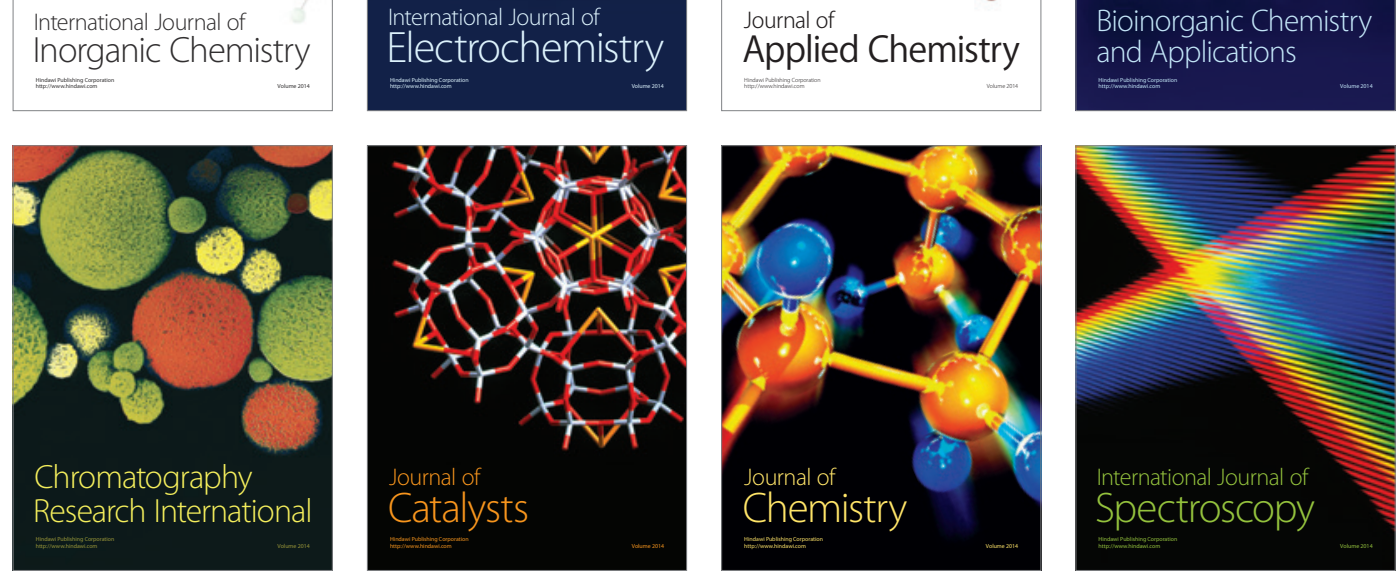